\title{
Delusions Increase Functional Impairment in Alzheimer's Disease
}

\author{
Corinne E. Fischer ${ }^{\mathrm{a}-\mathrm{c}} \quad$ Zahinoor Ismail ${ }^{c, e, f} \quad$ Tom A. Schweizer ${ }^{\mathrm{b}, \mathrm{d}}$ \\ ${ }^{a}$ Mental Health Service and 'Keenan Research Centre of the Li Ka Shing Knowledge Institute, St. Michael's \\ Hospital, 'Department of Psychiatry, University of Toronto, 'Division of Neurosurgery, St. Michael's Hospital and \\ University of Toronto, and ${ }^{e}$ Centre for Addiction and Mental Health, Geriatric Mental Health Program, Toronto, \\ Ont., and fDepartment of Psychiatry, University of Calgary, Calgary, Alta., Canada
}

\author{
Key Words \\ Dementia • Delusions · Alzheimer's disease $\cdot$ Functional \\ impairment $\cdot$ Caregiver burden $\cdot$ Behaviour
}

\begin{abstract}
Background/Aims: Delusions in Alzheimer's disease (AD) may be associated with functional impairment. No studies to date have used functional instruments sensitive to changes in frontal executive function, possibly underestimating the impact. Methods: Patients with AD with and without delusions were administered cognitive tests and questionnaires to assess depression and quality of life. Caregivers were administered questionnaires to assess functional impairment, caregiver burden and behavioural symptoms. Results: AD patients with delusions $(n=19)$ when compared to AD patients without delusions $(n=19)$ matched for age, education and global cognitive function were significantly more functionally impaired based on performance on the Disability Assessment for Dementia Scale $(p<0.005)$. Conclusion: AD patients with delusions have significantly worse functional performance.

Copyright $\odot 2012$ S. Karger AG, Basel
\end{abstract}

\section{Introduction}

Delusions are common symptoms in patients with Alzheimer's disease (AD). In fact, recent estimates sug- gest that approximately one third of patients with $\mathrm{AD}$ may develop delusions at some point during the course of the disease [1]. While these symptoms may be common, prior research suggests that they may be associated with a number of adverse health outcomes, including increased morbidity/mortality and premature institutionalization $[2,3]$. In spite of the prevalence of these symptoms and their association with adverse health outcomes, there has been comparatively little systematic research on how these symptoms affect clinical outcomes.

Much of the prior research assessing delusions in $\mathrm{AD}$ has attempted to localize delusions neuroanatomically. Past studies have consistently demonstrated an association with frontal executive dysfunction on neuropsychological testing. In a recent study, Nagata et al. [4] examined 48 patients with $\mathrm{AD}$ divided into two groups, namely those with and without delusions. After matching for age, sex, duration of illness and Mini-Mental State Examination (MMSE) score, they found a strong correlation between the presence of persecutory delusions and performance on the Japanese version of the frontal assessment battery. While these findings were of interest, the study did not attempt to correlate the difference in frontal executive function with relevant non-cognitive outcomes such as functional impairment, caregiver burden, quality of life and behavioural symptom severity. Frontal lobe findings have also been confirmed neuropathologically. Zubenko et al. [5] examined post-mortem

\section{KARGER \\ Fax +41613061234 \\ E-Mail karger@karger.ch}

www.karger.com
(C) 2012 S. Karger AG, Basel

$1420-8008 / 12 / 0336-0393 \$ 38.00 / 0$

Accessible online at:

www.karger.com/dem
Corinne E. Fischer

17044 cc wing, St. Michael's Hospital

30 Bond St.

Toronto, ON M5B 1W8 (Canada)

Tel. +1 416864 5320, E-Mail FISCHERC@smh.ca 
brain tissue of delusional and non-delusional AD patients and found a much higher concentration of senile plaques and neurofibrillary tangles in the middle frontal cortex of delusional AD patients when compared to non-delusional controls. Neuroimaging studies have produced similar results. Ismail et al. [6] recently conducted a comprehensive review of neuroimaging studies in delusional patients with $\mathrm{AD}$. The review included structural imaging studies as well as functional imaging studies and showed a correlation between delusions in $\mathrm{AD}$ and hypofrontality, specifically in the right hemisphere. Matsuoka et al. [7] showed a correlation between delusional severity and hypoperfusion in the right anterior insula region using single-photon emission computed tomography imaging, suggesting that certain brain regions may modify symptom severity. Delusions have also been shown to correlate with lacunar infarcts in the basal ganglia [8], suggesting a possible neuroanatomical mechanism.

While the majority of research focusing on delusions in patients with $\mathrm{AD}$ suggests an association with malfunctioning of the frontal lobe, there has been considerably less focus on what this means clinically. In a recent review [9], we looked at studies comparing daily functioning in $\mathrm{AD}$ patients with and without delusions and found a correlation with impaired functioning, specifically in instrumental activity of daily living (IADL) performance, among $\mathrm{AD}$ patients with delusions compared to those without. Studies by Harwood et al. [10], Tekin et al. [11] and Liu et al. [12] all looked at functional outcome in $\mathrm{AD}$ patients with and without delusions using memory clinic samples. All three studies found worse functioning in the delusional $\mathrm{AD}$ subgroup compared to the non-delusional subgroup when controlling for global cognitive function. Other studies [13-15] found no such differences, although none of the studies conducted to date used instruments sensitive to picking up deficits in frontal lobe function. As impaired IADL performance is a common clinical marker of early $\mathrm{AD}$, we were interested in comparing delusional and non-delusional $\mathrm{AD}$ patients in terms of their functional status, using a functional instrument that is very sensitive to detecting neuropsychological deficits in frontal executive function and validated in patients with $\mathrm{AD}$, i.e. the Disability Assessment for Dementia Scale (DADS) [16]. While prior studies have examined this question [7], no studies have utilized instruments sensitive to neuropsychological deficits in frontal executive function, thus possibly underestimating the impact of delusions on functional performance. In addition, previous studies have suggested that delusions may be associated with greater behav- ioural symptoms and increased caregiver burden $[2,3$, 17], but no studies to date have examined these factors controlling for disease severity or in combination with functional measures. Based on the research done in this field, we hypothesized that delusional AD patients when compared to non-delusional controls would be more functionally impaired and have greater behavioural symptoms and increased caregiver burden for the same level of disease severity and that these differences would correlate neuropsychologically with frontal executive deficits.

\section{Methods}

This study received institutional approval from the St. Michael's Hospital Research Ethics Board. Participants were recruited from various outpatient clinics at St. Michael's Hospital, the Centre for Addiction and Mental Health and several affiliated Long Term Care Homes in Toronto. Participants were considered eligible for the study if they were over the age of 65 years, English speaking, met the National Institute of Neurological and Communicative Disorders and Stroke and the Alzheimer's Disease and Related Disorders Association criteria for $\mathrm{AD}$, had a baseline MMSE score greater than 16, had a caregiver available and had no history of significant sensory deficits that would interfere with neuropsychological testing. Participants were allowed to be on psychotropic medication provided that it had been started more than 1 month prior to inclusion in the study and they were clinically stable on it. Participants were excluded from this study if they were acutely delirious, suffered from a form of dementia other than $\mathrm{AD}$ or mixed dementia, had a significant history of substance abuse, psychiatric illness (such as schizophrenia or bipolar disorder), systemic or neurologic disease or were clinically depressed or medically unstable. After providing written informed consent, participants were screened for the presence of delusions. Delusions were detected using a clinical interview conducted by a qualified psychiatrist with the patient and caregiver and then confirmed using a behavioural scale (Behavioural Pathology in Alzheimer's Disease Rating Scale; BEHAVE-AD [18]) administered to the caregiver of the patient. In order for a patient to be confirmed as delusional, both a psychiatrist and neurologist had to assess the patient and come to agreement. In addition, patients needed to score above 1 on the delusional/ paranoid ideation section of the BEHAVE-AD, and delusions had to be present for a minimum of 1 month prior to assessment. Patients were considered non-delusional on the basis that no delusions had been detected up to 6 months prior to assessment.

Different aspects of cognitive functioning, including memory, language, attention and executive functioning, were assessed through a series of neuropsychological tests and questionnaires. Patients were administered the National Adult Reading Test [19, 20], Word List Generation [21], the Wisconsin Card Sorting Task [22], the MMSE [23], the Trail 
Table 1. Demographic/non-cognitive measures in delusional and non-delusional AD patients, controlling for age, education and MMSE scores

\begin{tabular}{|c|c|c|}
\hline Variable & Mean \pm SD & $\mathrm{p}$ value \\
\hline \multicolumn{3}{|l|}{ Age, years } \\
\hline Non-delusional & $76.58 \pm 6.327$ & 0.274 \\
\hline Delusional & $79.06 \pm 7.223$ & \\
\hline \multicolumn{3}{|l|}{ Years of education } \\
\hline Non-delusional & $13.94 \pm 3.929$ & 0.382 \\
\hline Delusional & $12.76 \pm 3.817$ & \\
\hline \multicolumn{3}{|c|}{ Quality of Life in AD Questionnaire } \\
\hline Non-delusional & $36.32 \pm 7.311$ & 0.451 \\
\hline Delusional & $35.74 \pm 7.187$ & \\
\hline \multicolumn{3}{|c|}{ Geriatric Depression Scale } \\
\hline Non-delusional & $4.47 \pm 3.533$ & 0.688 \\
\hline Delusional & $4.00 \pm 4.524$ & \\
\hline \multicolumn{3}{|c|}{ Dysexecutive Questionnaire } \\
\hline Non-delusional & $18.79 \pm 11.655$ & 0.747 \\
\hline Delusional & $18.78 \pm 12.845$ & \\
\hline \multicolumn{3}{|l|}{ DADS } \\
\hline Non-delusional & $80.11 \pm 16.108$ & 0.011 \\
\hline Delusional & $54.44 \pm 25.033$ & \\
\hline \multicolumn{3}{|l|}{ DADS - basic ADLs } \\
\hline Non-delusional & $94.06 \pm 15.910$ & 0.071 \\
\hline Delusional & $72.50 \pm 34.692$ & \\
\hline \multicolumn{3}{|l|}{ DADS - IADLs } \\
\hline Non-delusional & $72.11 \pm 20.237$ & 0.007 \\
\hline Delusional & $41.56 \pm 23.951$ & \\
\hline \multicolumn{3}{|l|}{ DADS - leisure } \\
\hline Non-delusional & $80.83 \pm 25.103$ & 0.156 \\
\hline Delusional & $55.00 \pm 40.909$ & \\
\hline \multicolumn{3}{|l|}{ BEHAVE-AD } \\
\hline Non-delusional & $2.83 \pm 2.572$ & 0.001 \\
\hline Delusional & $14.22 \pm 9.033$ & \\
\hline \multicolumn{3}{|c|}{$\begin{array}{l}\text { BEHAVE-AD - paranoid and } \\
\text { delusional ideation }\end{array}$} \\
\hline Non-delusional & $0.28 \pm 0.669$ & 0.000 \\
\hline Delusional & $5.33 \pm 3.430$ & \\
\hline \multicolumn{3}{|c|}{ BEHAVE-AD - hallucinations } \\
\hline Non-delusional & $0.06 \pm 0.236$ & 0.052 \\
\hline Delusional & $1.50 \pm 2.065$ & \\
\hline \multicolumn{3}{|c|}{ BEHAVE-AD - activity disturbances } \\
\hline Non-delusional & $0.67 \pm 1.085$ & 0.091 \\
\hline Delusional & $1.83 \pm 1.689$ & \\
\hline \multicolumn{3}{|c|}{ BEHAVE-AD - aggressiveness } \\
\hline Non-delusional & $0.11 \pm 0.323$ & 0.003 \\
\hline Delusional & $1.33 \pm 1.237$ & \\
\hline \multicolumn{3}{|c|}{$\begin{array}{l}\text { BEHAVE-AD - diurnal rhythm } \\
\text { disturbances }\end{array}$} \\
\hline Non-delusional & $0.11 \pm 0.323$ & 0.179 \\
\hline Delusional & $0.67 \pm 1.085$ & \\
\hline \multicolumn{3}{|c|}{ BEHAVE-AD - affective disturbances } \\
\hline Non-delusional & $0.44 \pm 0.856$ & 0.011 \\
\hline Delusional & $1.83 \pm 2.007$ & \\
\hline \multicolumn{3}{|c|}{ BEHAVE-AD - anxieties and phobias } \\
\hline Non-delusional & $0.89 \pm 0.963$ & 0.354 \\
\hline Delusional & $1.11 \pm 1.079$ & \\
\hline
\end{tabular}

Table 1. (continued)

\begin{tabular}{lll}
\hline Variable & Mean \pm SD & p value \\
\hline Caregiver Burden Scale & & \\
$\quad$ Non-delusional & $24.31 \pm 13.676$ & 0.048 \\
$\quad$ Delusional & $34.82 \pm 15.424$ & \\
MMSE & & \\
$\quad$ Non-delusional & $22.05 \pm 2.121$ & 0.408 \\
$\quad$ Delusional & $20.58 \pm 3.580$ & \\
\hline
\end{tabular}

Making Test [24], the Boston Naming Test [25], the Token Test [26] and the California Verbal Learning Test (CVLT) [27]. Questionnaires such as the Dysexecutive Questionnaire [28], the Geriatric Depression Scale [29] and the Quality of Life in $\mathrm{AD}$ Questionnaire [30] were also administered to the patients to assess behaviour, mood and quality of life. Caregivers were asked to complete a series of questionnaires designed to measure behaviour (BEHAVE-AD [18]), daily functioning (DADS [16]) and caregiver burden (Caregiver Burden Scale [31]). Where available, patients were also compared in terms of psychotropic medication, including the numbers on cognitive enhancers and antipsychotic medications. The research assistant who administered the neuropsychological tests and questionnaires was blind to the delusional status of the patient at all times. Delusional and non-delusional AD participants matched for age and MMSE were then compared using an analysis of variance that controlled for the confounding effects of age, education and MMSE with SPSS 16.0 software. Significance was set at $\mathrm{p} \leq 0.05$. All analyses were two tailed.

\section{Results}

A total of $49 \mathrm{AD}$ patients meeting the eligibility criteria were recruited into the study and completed testing. Of these, 11 were later excluded, 9 because of incomplete testing and 2 because their MMSE scores were considered too high (26/30). In total, data for 38 patients were analyzed. Nineteen were non-delusional while 19 had delusions that had been present within 6 months of the assessment. Medication information was available for 13 non-delusional and 11 delusional AD patients. Eleven non-delusional versus 8 delusional $\mathrm{AD}$ patients were on cognitive enhancers, while 3 non-delusional and 5 delusional patients were on antipsychotic medications. One patient in each group was on no psychotropic medication, while data were missing for 8 non-delusional and 6 delusional AD patients. There were no significant differences noted between the two groups in terms of age, education or global cognitive function (MMSE score; table 1). In terms of other non-cognitive measures, sig- 
Table 2. Cognitive measures in delusional and non-delusional $\mathrm{AD}$ patients, controlling for age, education and MMSE scores

\begin{tabular}{|c|c|c|}
\hline Variable & Mean \pm SD & $\mathrm{p}$ value \\
\hline \multicolumn{3}{|c|}{$\begin{array}{l}\text { National Adult Reading Test - } \\
\text { errors }\end{array}$} \\
\hline Non-delusional & $33.39 \pm 16.500$ & 0.802 \\
\hline Delusional & $35.94 \pm 14.285$ & \\
\hline \multicolumn{3}{|c|}{ National adult reading test - FSIQ } \\
\hline Non-delusional & $101.76 \pm 12.870$ & 0.802 \\
\hline Delusional & $99.77 \pm 11.142$ & \\
\hline \multicolumn{3}{|c|}{ Trail Making Test A - sample time } \\
\hline Non-delusional & $11.37 \pm 6.272$ & 0.369 \\
\hline Delusional & $14.25 \pm 6.880$ & \\
\hline \multicolumn{3}{|c|}{ Trail Making Test A - time } \\
\hline Non-delusional & $60.74 \pm 30.160$ & 0.611 \\
\hline Delusional & $77.87 \pm 92.058$ & \\
\hline \multicolumn{3}{|c|}{ Trail Making Test B - sample time } \\
\hline Non-delusional & $23.76 \pm 14.417$ & 0.126 \\
\hline Delusional & $43.62 \pm 40.574$ & \\
\hline \multicolumn{3}{|c|}{ Trail Making Test B - time } \\
\hline Non-delusional & $290.25 \pm 265.420$ & 0.804 \\
\hline Delusional & $270.30 \pm 192.549$ & \\
\hline \multicolumn{3}{|c|}{ Trail Making Test B - errors } \\
\hline Non-delusional & $2.62 \pm 2.022$ & 0.142 \\
\hline Delusional & $1.50 \pm 1.434$ & \\
\hline \multicolumn{3}{|c|}{ Trail Making Test - B minus A } \\
\hline Non-delusional & $229.51 \pm 263.756$ & 0.899 \\
\hline Delusional & $219.81 \pm 188.607$ & \\
\hline \multicolumn{3}{|l|}{ CVLT - short delay } \\
\hline Non-delusional & $1.00 \pm 1.609$ & 0.383 \\
\hline Delusional & $0.87 \pm 1.060$ & \\
\hline \multicolumn{3}{|l|}{ CVLT - long delay } \\
\hline Non-delusional & $0.89 \pm 1.323$ & 0.851 \\
\hline Delusional & $0.67 \pm 1.175$ & \\
\hline \multicolumn{3}{|l|}{ CVLT - total } \\
\hline Non-delusional & $19.56 \pm 6.382$ & 0.690 \\
\hline Delusional & $18.13 \pm 7.279$ & \\
\hline \multicolumn{3}{|l|}{ Boston Naming Test } \\
\hline Non-delusional & $42.69 \pm 12.758$ & 0.144 \\
\hline Delusional & $35.78 \pm 11.202$ & \\
\hline \multicolumn{3}{|l|}{ Fluency - total } \\
\hline Non-delusional & $27.21 \pm 9.508$ & 0.166 \\
\hline Delusional & $21.39 \pm 12.210$ & \\
\hline \multicolumn{3}{|l|}{ Fluency - first $15 \mathrm{~s}$} \\
\hline Non-delusional & $011.05 \pm 4.731$ & 0.049 \\
\hline & $007.94 \pm 4.137$ & \\
\hline \multicolumn{3}{|l|}{ Fluency - last $45 \mathrm{~s}$} \\
\hline Non-delusional & $016.16 \pm 6.030$ & 0.349 \\
\hline Delusional & $013.44 \pm 8.396$ & \\
\hline \multicolumn{3}{|l|}{ Switches (total) } \\
\hline Non-delusional & $020.68 \pm 9.516$ & 0.044 \\
\hline Delusional & $14.56 \pm 8.590$ & \\
\hline \multicolumn{3}{|l|}{ Semantic (total) } \\
\hline Non-delusional & $9.42 \pm 3.626$ & 0.617 \\
\hline Delusional & $7.39 \pm 4.960$ & \\
\hline \multicolumn{3}{|l|}{ Token Test } \\
\hline Non-delusional & $36.26 \pm 6.665$ & 0.438 \\
\hline Delusional & $33.00 \pm 7.036$ & \\
\hline
\end{tabular}

Fluency was tested by Word List Generation. nificant differences between the two groups were noted for the DADS ( $p<0.05$ ), specifically the IADL subscale, BEHAVE-AD scores $(\mathrm{p}<0.005)$ and caregiver burden scores $(p<0.05)$. There were no differences noted between the two groups in terms of depression, frontal lobe behaviour or quality of life ( $p>0.05$ ).

In terms of neuropsychological status (table 2), there were significant differences noted between the two groups on measures of frontal lobe function, including phonemic fluency (first $15 \mathrm{~s}$ ) and total switches ( $\mathrm{p}$ $<0.05$ ). There were no differences noted between the two groups on other neurocognitive measures, including the National Adult Reading Test, Trails A and B, total fluency, semantic fluency and the CVLT. Unfortunately, not enough patients were able to complete the Wisconsin Card Sorting Test so we excluded it. We also looked at the correlation between subtests of the BEHAVE-AD, daily functioning and caregiver burden (table 3). All behavioural symptoms, with the exception of affective disturbances, diurnal rhythm disturbances and anxiety and phobias, appeared to affect function, both the total score and IADLs $(\mathrm{p}<0.01)$. Activity disturbances only mildly affected activities of daily living (ADLs; $\mathrm{p}<0.05$ ), and aggression did not correlate with ADLs at all. Affective disturbances correlated strongly with caregiver burden $(\mathrm{p}<$ 0.01 ), while anxieties/phobias and paranoid/delusional ideation correlated more weakly $(\mathrm{p}<0.05)$.

\section{Discussion}

Our study showed that $\mathrm{AD}$ patients with delusions had significantly worse functional performance compared to $\mathrm{AD}$ patients without delusions. This difference in functional performance was not explained by demographic or global cognitive status as the two groups were well matched on these variables and we ran an analysis of variance co-varying for age, education and MMSE. Interestingly, while the overall IADL subscale of the DADS showed significance, the basic ADL subscale did not. As the IADL subscale is much more closely correlated with frontal executive impairment, this further supports our argument that delusions are highly correlated with frontal executive dysfunction. While we attempted to get medication data for all patients retrospectively from electronic charts, we were not successful, and this does represent a limitation of the study. However, with regard to the medication information we were able to obtain, the groups were fairly evenly matched in terms of the numbers of patients on antipsychotic medications 
Table 3. Secondary analyses of BEHAVE-AD

\begin{tabular}{llllll}
\hline BEHAVE-AD & $\begin{array}{l}\text { Caregiver } \\
\text { Burden Scale }\end{array}$ & \multicolumn{2}{l}{ DADS } & & \\
\cline { 5 - 6 } & & total DADS & basic ADLs & IADLs & leisure \\
\hline Total BEHAVE-AD & $0.418^{* *}$ & $-0.500^{* *}$ & $-0.413^{* *}$ & $-0.574^{* *}$ & -0.218 \\
Paranoid and delusional ideation & $0.342^{*}$ & $-0.473^{* *}$ & $-0.465^{* *}$ & $-0.493^{* *}$ & -0.244 \\
Hallucinations & 0.154 & $-0.438^{* *}$ & $-0.436^{* *}$ & $-0.429^{* *}$ & -0.208 \\
Activity disturbances & 0.222 & $-0.441^{* *}$ & $-0.331^{*}$ & $-0.507^{* *}$ & -0.195 \\
Aggressiveness & 0.231 & $-0.400^{* *}$ & -0.276 & $-0.452^{* *}$ & $-0.338^{*}$ \\
Diurnal rhythm disturbances & 0.204 & -0.194 & -0.130 & -0.294 & 0.042 \\
Affective disturbance & $0.451^{* *}$ & -0.064 & 0.063 & -0.204 & -0.010 \\
Anxiety and phobias & $0.337^{*}$ & -0.085 & 0.067 & -0.229 & 0.146 \\
\hline
\end{tabular}

* Correlation is significant at the 0.05 level; ** correlation is significant at the 0.01 level.

and cognitive enhancers. It is therefore unlikely that differences in psychotropic medication use between the two groups had a significant impact on functional outcome. Furthermore, there were no significant differences noted between the two groups on traditional neurocognitive measures such as the CVLT, MMSE or Trail Making Test. In fact, patients with delusions performed better than controls on Trail Making Test B. However, there were significant differences noted on some subtests of frontal lobe function, including phonemic fluency (first $15 \mathrm{~s}$ ) and total switches. It has been argued by neuropsychologists that the first $15 \mathrm{~s}$ of the phonemic fluency task are more sensitive to frontal executive impairment. Although there were no significant differences in the total fluency score, this may have become significant with a larger sample size given that delusional patients on average produced 6 fewer words than non-delusional controls.

In keeping with our hypothesis, these results suggest that the worse functional status in $\mathrm{AD}$ patients with delusions in our study may have been mediated by worse frontal executive function neuropsychologically. It is possible that the changes detected would have been more significant if a more comprehensive neuropsychological battery had been used and if the sample size had been larger. Behavioural symptoms were also significantly worse in the delusional AD subgroup, as was caregiver burden, and it is possible that this was also mediated by impaired frontal executive function. These findings are also consistent with the literature, which suggests that psychotic symptoms in $\mathrm{AD}$ are often associated with greater caregiver burden [15]. The fact that there were no significant quality of life differences noted between the two groups and no differences on the frontal lobe ques- tionnaire (Dysexecutive Questionnaire) is somewhat more difficult to explain. It may be that changes were present but did not reach the threshold for significance and would have with a larger sample size. Another possibility is that delusions may correlate better with damage to the prefrontal cortex, which is more closely associated with problems with planning and multi-tasking and less closely associated with behaviour. Quality of life measures are notoriously unreliable in patients with frontal lobe damage given that patients often develop problems with awareness that may affect their assessment.

In terms of our secondary analyses, behavioural symptoms correlated very strongly with functional impairment, both ADLs and IADLs, and more weakly with caregiver burden. With respect to subtypes of behavioural symptoms, delusions, hallucinations, activity disturbance and aggression correlated strongly with functional impairment, while affective symptoms correlated less with functional impairment and more with caregiver burden. It is likely that neuropsychological impairments in frontal lobe function mediate both these subtypes of behavioural symptoms (delusions, hallucinations, activity disturbance and aggression) and functional decline. Affective disturbances in our study did not significantly correlate with changes in function but caused more distress for caregivers, second to delusions and other phobias. Apathy and mood changes have been well documented to be associated with significant caregiver stress based on previous research [32].

Our findings, namely that AD patients with delusions have significantly worse functional status, worse behavioural status and greater caregiver burden compared to $\mathrm{AD}$ patients without delusions, provide strong support 
for the existence of a psychotic subtype of AD. This is particularly the case given that the changes noted were independent of other cognitive measures of disease severity. In a recent review of this area, Ismail et al. [33] suggest that $\mathrm{AD}$ patients with delusions differ from those without delusions in terms of genetics, neurotransmitters, neuropathology and clinical course. They suggest that in fact different delusional subtypes (misidentification delusions vs. persecutory delusions) may have different neural mechanisms. In our study, we did not subtype patients based on their delusion type given the relatively small sample size. We also did not attempt to correlate dementia severity with delusional subtype. Research in this area by Sweet et al. [34], who compared AD patients with psychosis with those without psychosis, points to the existence of possible biomarkers. In a post-mortem magnetic resonance spectroscopy study, they found that AD patients with psychosis had greater neuropil disruption in multiple brain regions, including the dorsolateral prefrontal cortex, superior temporal gyrus and inferior parietal cortex. Similar accelerated biomarker changes have been shown in the anterior cingulate gyrus of $\mathrm{AD}$ patients with delusions compared to those without delusions [35].

The fact that $\mathrm{AD}$ patients with delusions had significantly worse functional performance in this study compared to those without delusions has implications for clinical care. AD patients with delusions should be screened more aggressively for the presence of functional impairment.

In addition, interventions that assist with function, such as increased community-based support, caregiver training and placement in a long-term care home, should be made available to such patients. Cognitive enhancers and AD-specific treatments should be administered as soon as possible, and change in function should be used to gauge improvement. Antipsychotic medications that have shown benefit in the treatment of delusions in $\mathrm{AD}$ and related dementias $[36,37]$ should be administered where appropriate. The high correlation between the presence of delusions, caregiver burden and other behavioural symptoms suggests that this subgroup may require more aggressive psychiatric management compared to other subtypes.

In conclusion, our study contributes to the growing body of literature suggesting that AD patients with delusions may represent a distinct subtype of the illness with unique biomarkers, neuropathology, genetics and clinical course. Future work in this area should continue to explore the clinical and neuroanatomical differences between $\mathrm{AD}$ patients with and without delusions.

\section{Acknowledgements}

This study was funded by the Alzheimer Society of Canada.

\section{References}

1 Ropacki SA, Jeste DV: Epidemiology of and risk factors for psychosis of Alzheimer's disease: a review of 55 studies published from 1990 to 2003. Am J Psychiatry 2005;162: 2022-2030.

- 2 Gormley N, Rizwan MR, Lovestone S: Clinical predictors of aggressive behaviour in Alzheimer's disease. Int J Geriatr Psychiatry 1998;13:109-115.

3 Harwood DG, Barker WW, Ownby RL, Duara R: Prevalence and correlates of Capgras syndrome in Alzheimer's disease. Int J Geriatr Psychiatry 1999;14:415-420.

4 Nagata T, Ishii K, Ito T, Aoki K, Ehara Y, Kada H, Furukawa H, Tsumura M, Shinagawa S, Kasahara H, Nakayama K: Correlation between a reduction in Frontal Assessment Battery scores and delusional thoughts in patients with Alzheimer's disease. Psychiatry Clin Neurosci 2009;63:449-454.
5 Zubenko GS, Moossy J, Martinez AJ, Rao G, Claassen D, Rosen J, Kopp U:Neuropathologic and neurochemical correlates of psychosis in primary dementia. Arch Neurol 1991; 48:619-624.

6 Ismail Z, Nguyen MQ, Fischer CE, Schweizer TA, Mulsant BH: Neuroimaging of delusions in Alzheimer's disease. Psychiatry Res 2012, E-pub ahead of print.

7 Matsuoka T, Narumoto J, Shibata K, Okamura A, Nakamura K, Okuyama C, Nishimura T, Fukui K: Insular hypoperfusion correlates with severity of delusions in individuals with Alzheimer's disease. Dement Geriatr Cogn Disord 2010;29:287-293.

-8 Palmqvist S, Sarwari A, Wattmo C, Bronge L, Zhang Y, Wahlund LO, Nagga K: Association between subcorticial lesions and behavioural and psychological symptoms in patients with Alzheimer's disease. Dement Geriatr Cogn Disord 2011:32:417-423.
\$9 Fischer CE, Verhoeff NP, Churchill K, Schweizer TA: Functional outcome in delusional Alzheimer disease patients. A systematic review. Dement Geriatr Cogn Disord 2009;27:105-110.

10 Harwood DG, Barker WW, Ownby RL, Duara R: Relationship of behavioral and psychological symptoms to cognitive impairment and functional status in Alzheimer's disease. Int J Geriatr Psychiatry 2000;15: 393-400.

11 Tekin S, Fairbanks LA, O’Connor S, Rosenberg S, Cummings JL: Activities of daily living in Alzheimer's disease: neuropsychiatric, cognitive, and medical illness influences. Am J Geriatr Psychiatry 2001;9:81-86.

12 Liu CY, Wang PN, Lin KN, Liu HS: Behavioural and psychological symptoms in Taiwanese patients with Alzheimer's disease. Int Psychogeriatr 2007;19:605-613. 
-13 Green CR, Marin DB, Mohs RC, Schmeidler J, Aryan M, Fine E, Davis KL: The impact of behavioral impairment of functional ability in Alzheimer's disease. Int J Geriatr Psychiatry 1999;14:307-316.

14 Mok WY, Chu LW, Chung CP, Chan NY, Hui SL: The relationship between non-cognitive symptoms and functional impairment in Alzheimer's disease. Int J Geriatr Psychiatry 2004;19:1040-1046.

15 Weiner MF, Hynan LS, Bret ME, White C 3rd: Early behavioral symptoms and course of Alzheimer's disease. Acta Psychiatr Scand 2005;111:367-371.

16 Gélinas I, Gauthier L, McIntyre M, Gauthier $S$ : Development of a functional measure for persons with Alzheimer's disease: the Disability Assessment for Dementia. Am JOccup Ther 1999;53:471-481.

17 Fischer CE, Ismail Z, Schweizer TA: Impact of delusions on caregiver burden in patients with Alzheimer's disease. Neurodegener Dis Manag 2012, in press.

18 Reisberg B, Borenstein J, Salob SP, Ferris SH, Franssen E, Georgotas A: Behavioral symptoms in Alzheimer's disease: phenomenology and treatment. J Clin Psychiatry 1987;48: 9-15

19 Nelson HE: National Adult Reading Test (NART): Test Manual, ed 2. Windsor, NFER Nelson, 1982

20 Blair JR, Spreen O: Predicting premorbid IQ: a revision of the National Adult Reading Test. Clin Neuropsychol 1989;3:129-136.

-21 Chertkow H, Bub D: Semantic memory loss in dementia of the Alzheimer's type. Brain 1990;113:397-417.

22 Heaton RK, Chelune GJ, Talley JL, Kay GG, Curtis G: Wisconsin Card Sorting Test (WCST) Manual, revised and expanded. Odessa, Psychological Assessment Resources, 1993.
23 Folstein MF, Folstein SE, McHugh PR: 'Mini-Mental State.' A practical method for grading the cognitive state of patients for the clinician. J Psychiatr Res 1975;12:189-198.

24 Reitan RM: The relation of the Trail Making Test to organic brain damage. J Consult Psychol 1955;19:393-394.

25 Kaplan EF, Goodglass H, Weintraub S: The Boston Naming Test: Experimental edition. Philadelphia, Lippincott Williams \& Wilkins, 1978, 1983.

26 Derenzi E, Vignolo L: The Token Test: a sensitive test to detect receptive disturbances in aphasics. Brain 1962;85:665-678.

27 Delis DC, Kramer JH, Kaplan E, Ober BA: California Verbal Learning Test, ed 2, adult version. San Antonio, The Psychological Corporation, 2000.

28 Wilson BS, Alderman N, Burgess PW, Emslie $\mathrm{H}$, Evans JJ: Behavioral Assessment of the Dysexecutive Syndrome. Bury St. Edmunds, Thames Valley Test Company, 1996.

29 Yesavage JA, Brink TL, Rose TL, Adey M: The Geriatric Depression Rating Scale: comparison with other self-report and psychiatric rating scales; in Poon LW (ed): Handbook of Clinical Memory Assessment of Older Adults. Washington, American Psychological Association, 1986, pp 153-167.

30 Logsdon RG, Gibbons LE, McCurry SM, Teri L: Quality of life in Alzheimer's disease: patient and caregiver reports. J Ment Health Aging 1999;5:21-32.

31 Zarit SH, Reeverm KE, Bach-Peterson J: Relatives of the impaired elderly: correlates of feelings of burden. Gerontologist 1980;20: 649-655.
>32 Karttunen K, Karppi P, Hiltunen A, Vanhanen M, Valimaki T, Martikainen J, Valtonen H, Sivenius J, Soininen H, Hartikainen S, Suhonen J, Pirttila T; ALSOVA study group: Neuropsychiatric symptoms and quality of life in patients with very mild and mild $\mathrm{Al}$ zheimer's disease. Int J Geriatr Psychiatry 2011;26:473-482.

33 Ismail Z, Nguyen MQ, Fischer CE, Schweizer TA, Mulsant BH, Mamo D: Neurobiology of delusions in Alzheimer's disease. Curr Psychiatry Rep 2011;13:211-218.

34 Sweet RA, Panchalingam K, Pettegrew JW, McClure RJ, Hamilton RL, Lopez OL, Kaufer DI, DeKosky ST, Klunk WE: Psychosis in Alzheimer's disease: postmortem magnetic resonance spectroscopy evidence of excess neuronal and membrane phospholipids pathology. Neurobiol Aging 2002;23: 547-553.

35 Shinno H, Inagaki T, Miyoka T, Okazaki S, Kawamukai T, Utani E, Inami Y, Horiguchi $\mathrm{J}$ : A decrease in $\mathrm{N}$-acetylaspartate and an increase in myoinositol in the anterior cingulated gyrus are associated with behavioral and psychological symptoms in Alzheimer's disease. J Neurol Sci 2007;260:132-138.

36 Fischer C, Bozanovic R, Atkins J, Rourke $\mathrm{S}$ : Treatment of delusions in dementia with Lewy bodies - response to pharmacotherapy. Dement Geriatr Cogn Disord 2007;23: 307-311.

\$37 Fischer C, Bozanovic R, Atkins J, Rourke $\mathrm{S}$ : Treatment of delusions in Alzheimer's disease - response to pharmacotherapy. Dement Geriatr Cogn Disord 2006;22: 260-266. 